\title{
The underutilized role of community gardens in improving cities' adaptation to climate change: A review
}

\author{
Mysha Clarke*, Melissa Davidson, Monika Egerer, Elsa Anderson, \\ Nakisha Fouch \\ Villanova University
}

\begin{abstract}
Green infrastructure is a salient approach to address climate change adaptation in cities. However, some green infrastructure like community gardens are rarely incorporated in resilience and adaptation plans. In this paper, we argue that community gardens should be a prioritized element of green infrastructure to improve adaptation to climate change. Community gardens can reduce urban heat islands, provide various ecosystem services, and increase storm water retention. From a socioeconomic perspective, these gardens also build trust, facilitate participation, improve responses to natural disasters and food security - all vital components of effective adaptation and resilience to climate change. Yet, our qualitative analysis of 18 policy documents for Baltimore, Chicago, and New York City, U.S.A, found that green infrastructure to improve climate change adaptation prioritizes rain gardens, bioswales, and green roofs, but seldom acknowledge the role of community gardens. Furthermore, community gardens historically emerged in these cities to respond to stressors like economic, social, and political instability. Therefore, policies that address climate change should explicitly incorporate community gardens.
\end{abstract}

Keywords: adaptive capacity; climate change adaptation; green infrastructure; urban greening.

\section{Introduction}

Social, ecological, and technological systems interact to create complex dynamics in cities. Cities are especially vulnerable to the adverse effects of climate change because of their high population densities, interdependence of socio-ecological systems, removal of natural protections, and constant change in urbanization (Wamsler et al., 2013). As a result, urban planning and management must account for changing interactions between people, climate, and infrastructure systems. Green infrastructure, and natural processes that are designed to manage storm water runoff in urban areas, can help with climate change adaptation and mitigation in cities (Gill et al. 2007; Mason and Matalto, 2015; Okvat and Zauta, 2011). Although city planners and policymakers also recognize the benefits of various urban green infrastructure such as bioswales and rain gardens to reduce their greenhouse gas emissions, mitigate climate 
p. 242. The underutilized role of community gardens in improving cities' adaptation to climate change: A review

change and increase overall resilience in cities (Andersson et al., 2014; Demuzere et al., 2014; Gill et al. 2007), urban community gardens, are rarely incorporated in these policies to improve climate change adaptation. Community gardens can reduce carbon emissions and energy dependence in urban areas (Okvat and Zauta, 2011; Dubbeling, 2015). Furthermore, it was estimated that 10,000 community gardens in the U.S. have sequestered 190,000 tons of carbon in the past ten years, thereby offsetting a year's worth of carbon emissions for 30,400 Americans (Okvat and Zauta, 2011). Urban community gardens can help restore vacant spaces, increase biodiversity and the provisioning of ecosystem services. In this paper, we focus on cities' adaptation to climate change, specifically as it relates to community-based adaptation (CBA) to climate change. CBA can include identifying and implementing programs and plans that improves communities' adaptive capacities and is designed based on the communities expressed desires and concerns, especially in vulnerable communities (Archer et al., 2014). In many cases, climate change planning and adaptation is done via top-down approaches. While this approach may be effective in some scenarios, climate change adaptation will be most effective when community perspectives and learning also play a significant role.

Policies that promote sustainable grassroots efforts and bottom-up approaches like community gardens can be a better approach to climate change adaptation than government mandates (Okvat and Zauta, 2011). Community gardens can offer a participatory approach to community development by providing a common space to build social networks (Okvat and Zauta, 2011; Passidomo, 2016; Walker et al., 2016), increase multicultural relations, inclusivity and interpersonal relations (Okvat and Zauta, 2011; Agustina and Beilin, 2012) and serving as a refuge for residents after a disaster (Chan et al., 2015) - important community characteristics to increase resilience (Okvat and Zauta, 2011). Community gardens can include a variety of stakeholders at various scales including government agencies, non-profit organizations, local community members etc. (Okvat and Zauta, 2012; Miller, 2003). They also increase participatory community development, community organizing and empowerment (Okvat and Zauta, 2011; Dubbeling, 2015; Agustina and Beilin 2012 Tidball and Krasny, 2007). Gardening can increase people's awareness, dependence on nature and create social capacity to learn. Furthermore, these community gardens can be viewed as an institution or network that contributes to social learning related to community development and food security (Barthel et al., 2010; Camps-Calvet et al., 2016 Tidball and Krasny 2007; Cretney, 2014). They may also increase property values in underprivileged communities in New York City (Been and Voicu, 2006). In addition to the socio-ecological benefits of urban community gardens, previous research and historical patterns show that these gardens also play pivotal roles during socio-economic stress events.

To better understand the importance of urban gardens as it relates to socioeconomic or ecological stressors, it is important to review the historical patterns of these green spaces. Historically, urban gardening has been a consistent strategy to address urban crises (Bassett, 1981; Lawson, 2005; Okvat and Zauta, 2011; Staeheli et al., 2002). For example, allotment gardens in Britain from 1873-1978 peaked during the Great World Wars (Barthel et al., 2015), while a parallel pattern emerged in the U.S.A. with the proliferation of Liberty and Victory Gardens (Lawson, 2005; Okvat and Zauta, 2011). Victory gardens were private and public gardens that were implemented during World Wars I and II for recreation, to increase food security and boost feelings of patriarchy. In the United States, community gardens also emerged in times of economic crises such as the subsistence gardens of the Great Depression, especially among low-income residents (Lawson, 2005; Okvat and Zauta, 2011). In the 1970s, gardening efforts reflected bottom-up, grassroots movements led by community residents and garden activists (Staeheli et al., 2002). This differed from the top-down 
p. 243. The underutilized role of community gardens in improving cities' adaptation to climate change: A review

nature of war era gardening that was incentivized by U.S. national policy (von Hassell 2005; Okvat and Zauta, 2011; Lawson, 2005). Today, as cities face climate related threats, studies show that community gardens that are initiated through a bottom-up approach may effectively empower citizens to be better adapted to threats from climate change (Mason and Matalto, 2015; Walker, 2016). In fact, community gardens can provide a valuable space for community members to be more active, build trust, and take more initiative - important traits that can make communities stronger and more resilient (Okvat and Zauta, 2011). Over time, particularly during periods of socioecological stress, urban community gardens have emerged to counter some of those shocks in urban communities.

Cities have a unique challenge and opportunity for climate change adaptation because of their concentration of human capital and resources, high population densities and rapidly increasing population sizes. Although individual policy analyses shed light on climate change adaptation of cities in the future (McPhearson et al., 2014), few have compared multiple cities of diverse histories and variable challenges (Tanner et al., 2009; Shaw and Maythorne, 2012). Even fewer have explored how community gardens are incorporated into policies that address climate change (Dubbeling, 2015). Thus, research is needed to better understand how adaptation to climate change is operationalized in different policies (Wilkinson, 2012; Shaw, 2012); particularly the role of green infrastructure like urban community gardens. In this review, we aim to assess the role of community gardens in city policies to address climate change. In this paper, we argue that community gardens are underutilized to address adaptation to climate change, build community and adaptive capacity. To support our argument, we will, 1) summarize the historic emergence of urban community gardens and 2) assess how these gardens are incorporated in the plans to address climate change in Chicago, New York City and Baltimore, USA. To do this, we asked: 1) how do cities define and frame resilience to climate change? 2) do cities view gardens as a viable way to aid climate change mitigation and adaptation? and 3) what are the opportunities for community gardens to improve overall climate change resilience in cities?

\section{Methods}

\section{Policy review of three US cities' approach to climate change}

We compared the historical role of community gardens in relation to their current role in city plans and policies that address resilience to climate change. We selected three cities in the USA to perform the historical analysis and policy review: Baltimore, MD; Chicago, IL; and New York City, NY. We selected these three cities because: 1) each city currently has a large number of community gardens and a rich history of urban gardens dating back to the late 1800s; 2) all current Mayors are committed to addressing climate change (e.g., all Mayors signed the Paris Climate Agreement - an agreement within the United Nations Framework Convention on Climate Change to combat climate change); 3) each city has implemented a "Climate Action Plan" (within 5 years) that outlines the city-specific impacts of climate change and provides strategies to address them.

We did a qualitative assessment of city plans and policies about climate change resilience and community gardens (Table 1). We identified and selected relevant policy documents by reviewing city government websites and identifying policies, planning documents and reports related to sustainability, green infrastructure and urban agriculture, including community gardens. 
p. 244. The underutilized role of community gardens in improving cities' adaptation to climate change: A review

Table 1: Data sources and policy documents analyzed for Chicago, Baltimore and New York City

\begin{tabular}{|c|c|c|}
\hline City & Plan & Department \\
\hline Baltimore & $\begin{array}{l}\text { - } \text { Climate Action Plan (2013) } \\
\text { - }(2009) \\
\text { - } \text { Homegrown Baltimore Plan (2013) } \\
\text { - } \quad \text { Baltimore Disaster Preparedness and } \\
\text { - } \text { Planning Project (2013) } \\
\text { - } \text { Baltimore Food Policy Initiative (BFPI) } \\
\text { Green Pattern Book (2015) }\end{array}$ & $\begin{array}{l}\text { - Baltimore Department of } \\
\text { Planning, Office of } \\
\text { Sustainability } \\
\text { - City Planning Commission }\end{array}$ \\
\hline Chicago & $\begin{array}{l}\text { - Climate Action Plan } \\
\text { - Chicago Eat Local Live Healthy (2004) } \\
\text { - } \text { Climate Resilience Strategy Paper } \\
\text { - Integrating Green Infrastructure } \\
\text { Chicago }\end{array}$ & $\begin{array}{l}\text { - Sustainable Development } \\
\text { Division } \\
\text { - Department of Planning \& } \\
\text { Development } \\
\text { - City of Chicago Department of } \\
\text { Planning and Development } \\
\text { - Chicago Metropolitan Agency } \\
\text { for Planning } \\
\text { - Environmental Protection } \\
\text { Agency (EPA) }\end{array}$ \\
\hline New York & $\begin{array}{l}\text { One New York: The Plan for a Just and } \\
\text { Strong City (2015) } \\
\text { - Vision 1: Our Growing, Thriving } \\
\text { City } \\
\text { - Vision 2: Our Just and Equitable } \\
\quad \text { City } \\
-\quad \text { Vision 3: Our Sustainable City } \\
-\quad \text { Vision 4: Our Resilient City } \\
\text { - } 1.5^{\circ} \text { C: Aligning New York City with the } \\
\text { Paris Climate Agreement (2017) } \\
\text { - New York City Food Policy }\end{array}$ & $\begin{array}{l}\text { - Mayor's Office of Sustainability } \\
\text { - Environmental Protection } \\
\text { reports }\end{array}$ \\
\hline
\end{tabular}

We analyzed 18 policy documents and reports using QSR International's Nvivo 10, a qualitative data analysis software (Table 2). Using NVivo we read, coded and assigned themes to each document using a mix of deductive and inductive methods. Each city policy had already established overarching topics or themes for their climate change resilience efforts including land use, pollution, food security, and energy supply. We used these already established themes in our codes and further divided them into subthemes. Additional codes that emerged from the policy documents which were not explicitly categorized in the documents as important themes were identified inductively. Examples of such inductive themes are: collaborations or partnerships, environmental justice, policy recommendations, threats to gardens, the role of community gardens and the role of government. 
p. 245. The underutilized role of community gardens in improving cities' adaptation to climate change: A review

\section{Results and Discussion}

\section{Cities' definitions and perceptions of resilience to climate change}

Improving resilience to climate change is a key component of city policies in Baltimore, Chicago, and New York City. However, we believe it is also problematic that these policy documents did not provide an explicit definition of resilience. The major themes identified in their climate change resilience policies include engineering, ecological, economic, and community resilience and adaptive capacity. Environmental justice and equity were also identified as important goals. In Baltimore, the primary overarching goals are: energy savings and supply, land use \& transportation and growing a green city. Chicago's five overarching goals for their Climate Action Plan are: 1) energy efficient buildings; 2) clean and renewable energy sources; 3) improved transportation options; 4) reduced waste and industrial pollution; and 5) adaptation (Table 2). These five primary goals are subdivided into thirty-five strategies which cumulates to improving the city's resilience to climate change (Table 1). In New York City, the main Climate Action goals include reduced and more efficient consumption and transition to clean energy. For example, the One New York City plan outlines 4 components to build: 1) a growing, thriving city; 2) just and equitable city; 3) sustainable city; and 4) resilient city. NYC's main goals are to improve resilience in neighborhoods, buildings, infrastructure and coastal defense. Baltimore's three primary climate action goals are: 1) energy savings and supply; 2) land use and transportation; and 3) growing a green city.

In terms of ecological resilience to climate change, these cities focus on ways to improve coastal ecosystems, protect natural resources, and improve water quality. On the other hand, community resilience to climate change focuses primarily on improving the communities' response to natural hazards like floods, extreme heat and coastal storms. Overall, these plans included funding projects that will develop community resilience by protecting natural resources and resilient communication systems. Although community resilience to climate change is important, strategies prioritized at the city level for improving community resilience are more concerned with infrastructure and community response post-disaster rather than pre-disaster preparation. For example, Baltimore plans to grow a green city by developing "a comprehensive recycling plan, reduce construction and demolition waste, repair water supply infrastructure and increase the number of trees planted." Although these strategies may be effective, we also believe that this is a missed opportunity to incorporate community gardens because it could help green the city, develop sociocultural capacities and make communities more adaptable to climate change related threats.

Overall, the policies of these three cities focus primarily on reactive forms of resilience (coping with and adjusting to stressors), which strengthens response for recovery management (Vale, 2014). The priorities of these climate change resilience policies are like those of the United Kingdom that focus on reactive responses and the mobilization of public safety institutions (Mehmood, 2016). This policy approach is in opposition to other dominant community resilience strategies identified in the scientific literature which focuses on increasing social trust, community cohesion and adaptive capacity (Chaskin, 2008). While reactive strategies are important, this approach to community resilience does not adequately empower the community pre-disasters. An innovative, proactive approach would create opportunities to improve community capacity and climate change resilience, thereby resulting in less-severe outcomes in the event of a natural disaster or other stressor. Urban community gardens can serve as an example of a proactive space and should be encouraged in planning and policy. 
p. 246. The underutilized role of community gardens in improving cities' adaptation to climate change: A review

The focus of climate change resilience in Baltimore, Chicago, and NYC prioritizes resilience according to the disciplines of engineering and economics because of the focus on infrastructure development, design, energy and improved technology. While this approach is important to climate change resilience, it also provokes other considerations about whether this approach will provide equitable distribution of resources across cities including the impacts on disadvantaged and socio-economically vulnerable communities (Vale, 2014; Leichenko, 2011).

\section{The perceptions of community gardens are in climate change policies of Chicago, Baltimore and New York City}

\section{Brief history of community gardens in Baltimore, Chicago and New York City}

Baltimore, Chicago and New York City have similar histories of urban garden movements that can be sub-divided into four main phases. Community gardening started between 1890 and 1917 with the early urban gardens program (Lawson, 2005). These early gardens were created during a transitory period of increased urbanization and industrialization, especially on the East Coast of the U.S. Vacant lot cultivation, school gardens, and civic gardens during this period provided a way to beautify cities, provide employment and food security for the urban poor while reducing environmental exploitation, urban congestion and economic instability (Lawson, 2005). These early gardens were mostly created by welfare reformers and improvement societies.

Community gardening continued with the Liberty and Victory gardens that were popular from 1917 to 1945 . These gardens were created during World War I and II and aimed to create a shared national identity by encouraging public participation. These gardening efforts were primarily organized by the federal government to boost morale, increase domestic food production and reduce malnutrition. In fact, Victory Gardens provided 40 per cent of the national supply of vegetables in 1944 (Lawson, 2005). Urban gardening continued into the 1970s economic recession and environmental movement. Unlike previous years that focused on private, residential or school gardens, the gardening movement of the 1970s focused more on public community gardens and was spearheaded by local community groups and garden activists. The community gardens of this period were motivated by political activism, community revitalization, and economic activity (Lawson, 2005). For example, between 1970 and 1990, community gardens sprang up in poorer communities like the Lower East Side (NYC) in abandoned vacant properties (von Hassel, 2002; Staeheli et al., 2002).

Although Baltimore, Chicago, and New York City all have a rich history of community gardening that emerged in response to various social, economic and environmental stressors, it is surprising that community gardens are not more explicitly used to address the current threats of climate change. None of the Climate Action Plans in these cities have an explicit role for community gardens as a strategy to address climate change, or to improve social-ecological resilience. Food and agriculture policies in these cities identified a role for community gardens as spaces to build community, improve food security and food resilience. However, community gardens are not perceived as strategies to contribute to climate change resilience in these cities and are therefore not advocated as such.

In contexts where gardens of any kind are mentioned in policy documents with regards to resilience, they are primarily referred to as mechanisms to improve green spaces and storm water run-off and usually specifies rain gardens, bioswales and green roofs, not food-producing community gardens. For example, in New York City, the 
p. 247. The underutilized role of community gardens in improving cities' adaptation to climate change: A review

“Gardens Rising" project was created and funded with \$2 million USD to improve storm water runoff in the city through the implementation of rain gardens, bioswales, and permeable pavement. Although food policies and previous studies identify community gardens as avenues to produce food, engage the community and provide nutritional information, they are largely omitted in formal climate resilience planning. Although food policies acknowledge that community gardens can improve community engagement, it is also important to recognize that these spaces can also encourage informal management and stewardship of green spaces, resulting in more resilient cities (Biggs et al., 2012). Although many community gardens emerged in response to economic crisis in the past, we also acknowledge that many are suppressed after conditions improve. In many cases, urban community gardens are highly contested spaces because private and public entities debate the right to use vacant city properties (Staeheli et al., 2002; Staeheli, 2008). Furthermore, gardens are also regarded as political spaces because they create a unique avenue for residents to assert their rights to the city and urban landscape (Staeheli et al. 2002; Ghose and Pettygrove, 2014; Purcell and Tyman, 2014). Owing to the vulnerability of urban community gardens, city policies should create and nurture opportunities for gardens to contribute to climate change adaptation.

\section{Opportunities for community gardens to contribute to climate change resilience in city policies}

Each city has their own agriculture program dedicated to increasing food access and food resilience. For example, Homegrown Baltimore is the city's urban agriculture program. It acknowledges that community gardens can increase the availability of fresh local produce, develop the local economy, improve the natural environment, convert vacant lots to productive uses, provide educational opportunities and improve community resilience. While these benefits are explicitly stated in Baltimore's food policy, there is a disconnect in incorporating community gardens in large scale policies for addressing climate change resilience. Indirectly, community gardens can connect people to their natural environment, educate them about climate change by demonstrating how food choices can impact the climate, and foster a connection between people and their environment (Okvat and Zauta, 2011).

Despite the diverse benefits of community gardens, we acknowledge that they are not a panacea for socio-ecological resilience to climate change. Although integrating community gardens as a green infrastructure in Climate Action Plans can beneficially incorporate both social and ecological systems (Alberti et al., 2003; Dennis et al., 2016), urban agriculture may be socially divisive if they are used by new primary industries or as a temporary "fix" to structural inequalities (Colasanti et al., 2012) or as a sustainability fix (Walker, 2016). For example, urban agriculture research in Detroit, USA and Vancouver, Canada argues that gardens can used as a grassroots initiative to encourage economic and food justice while simultaneously promoting neoliberalism, thereby creating a sustainability fix in these cities (Walker, 2016). Therefore, policies must ensure that gardens are organic, do not evolve into emitters of greenhouse gases, and refrain from discriminatory or exclusive practices (Okvat and Zauta, 2011). Policies can reduce barriers to creating and maintaining community gardens, create incentives to establish community gardens, provide land tenure to gardens, and support community garden-specific needs (Okvat and Zauta, 2011). Thus, although community gardens can strategically improve the resilience of ecosystem services and climate change, they are currently an underutilized resource in city policies and planning because cities may prefer relatively low-management green infrastructure such as bioswales. 
p. 248. The underutilized role of community gardens in improving cities' adaptation to climate change: A review

Unfortunately, community gardens can also be transitory, particularly when the host cities do not support and invest in them. The lack of government support and the ephemerality of many community gardens (Staeheli et al., 2002; Staeheli, 2008) may make it challenging to include them in policies to address climate change in cities. Therefore, we emphasize that cities will need long-term planning and investment that may be difficult for elected government officials to operationalize given that their success might be based on reducing rather than adapting to disasters (Vale, 2014). Unlike the other forms of green infrastructure like green roofs and bioswales which are usually managed by the city governments, community gardens may provide a decentralized approach to building social and ecological resilience. Furthermore, we also acknowledge that cities might not have enough resources to successfully establish and maintain urban community gardens. Because of these complex socio-economic and political factors, it is critically important that approaches to improve climate change adaptation are community-oriented and solicit community participation.

\section{Conclusion}

Historically, community gardens emerged as powerful responses to economic or political crises. Today, they are not acknowledged in city policies to address climate change and are therefore underutilized in resilience planning. We found that Baltimore, Chicago and New York City (USA), tend to focus on green infrastructure like green roofs, bioswales and rain gardens that are all primarily managed by city officials and unfortunately misses an opportunity to engage the community. Nonetheless, studies repeatedly show that community managed green infrastructure like community gardens have multiple socio-ecological benefits and promote the participation of community stakeholders by increasing their overall adaptive capacity for climate change. The disconnect between historical uses of gardens and today's city policies, provokes several questions. First, who gets to make decisions about the use of green spaces and the types of green spaces? This is a particularly important consideration because majority of urban community gardens are in established in primarily low income, community of color. Second, how can cities be more adaptive to climate change without relying solely on reactive responses to disaster events? Since our paper focused on community gardens, research is needed to better understand whether private gardens may provide similar benefits to improving community-based adaptation to climate change. Empirical research can also investigate the attitudes, perspectives and goals of policy makers in various cities about how the decision-making process related to funding for climate change adaptation.

Community gardens should be actively integrated in city plans as a proactive way to improve climate change adaptation. Gardens can help communities develop their adaptive capacities and community resilience before climate-related threats occur, and better adapt post disaster. We found that despite the pivotal role urban community gardens played in response to socio-economic or environmental stressors in these cities, they are still underutilized and primarily unprotected spaces. Policy makers should seriously consider the role of community gardens in strategies to address climate change resilience because they have a historical precedence of providing a community space during various socio-economic stressors. If we are to be better adapted to climate change, we should incentivize, establish and protect community spaces like urban community gardens that promotes community-based adaptation in numerous capacities. 
p. 249. The underutilized role of community gardens in improving cities' adaptation to climate change: A review

\section{Acknowledgements}

We acknowledge support provided by the National Socio-Environmental Synthesis Center (SESYNC) for the Graduate Pursuit Program funded through NSF grant no. DBI1052875.

*Correspondence address: Dr. Mysha Clarke, Villanova University, Department of Geography and the Environment, 800 Lancaster Ave, Villanova, PA 19085, USA. Email: mysha.clarke@villanova.edu

\section{References}

Agustina, I. and Beilin, R. (2012) Community Gardens: Space for Interactions and Adaptations. Procedia - Social and Behavioral Sciences, 36, 439-448.

Alberti, M., Marzluff, J.M., Shulenberger, E., Bradley, G., Ryan, C. and Zumbrunnen, C. (2003) Integrating humans into ecology: Opportunities and challenges for studying urban ecosystems. BioScience, 53, 1169-1179.

Andersson, E., Barthel, S., Borgström, S., Colding, J., Elmqvist, T., Folke, C. and Gren, Å. (2014) Reconnecting cities to the biosphere: Stewardship of green infrastructure and urban ecosystem services. Ambio, 43, 4, 445-453.

Archer, D., Almansi, F., DiGregorio, M., Roberts, D., Sharma, D. and Syam, D. (2014) Moving towards inclusive urban adaptation: Approaches to integrating communitybased adaptation to climate change at city and national scale. Climate and Development, 6, 4, 345-356.

Baltimore Department of Planning, Office of Sustainability (2015) Green pattern book: using vacant land to create greener neighborhoods in Baltimore. NRS-INF-32-15. Newtown Square, PA: U.S. Department of Agriculture, Forest Service, Northern Research Station: 109.

Barthel, S., Folke, C. and Colding, J. (2010) Social-ecological memory in urban gardens - Retaining the capacity for management for ecosystems services. Global Environmental Change, 20, 255-265.

Barthel, S., Parker, J. and Ernston, H. (2015) Food and Green Space in Cities: A Resilience Lens on Gardens and Urban Environmental Movements. Urban Studies, 52, 7, 1321 - 1339.

Bassett, T. J. (1981) Reaping on the margins: a century of community gardening in America. Landscape, 25, 2, 1-8.

Been, V. and Voicu, I. (2006) The effect of community gardens on neighboring property values. New York University Law and Economics Working Papers [online]. Available at: http://Isr.nellco.org/nyu lewp/46 [Accessed: 23/11/2018]

Biggs, R., Schlüter, M., Biggs, D., Bohensky, E.L., BurnSilver, S., Cundill, G. and West, P.C. (2012) Toward principles for enhancing the resilience of ecosystem services. Annual Review of Environment and Resources, 37, 10, 421-5938.

Camps-Calvet, M., Langemeyer, J., Calvet-Mir, L. and Gómez-Baggethun, E. (2016) Ecosystem services provided by urban gardens in Barcelona, Spain: Insights for policy and planning. Environmental Science and Policy, 62, 14-23.

Chan, J., Dubois, B. and Tidball, K.G. (2015) Refuges of local resilience: Community gardens in post-Sandy New York City. Urban Forestry \& Urban Greening, 14, 3, 625-635.

Chaskin, R.J. (2008) Resilience, community, and resilient communities: conditioning contexts and collective action. Child care in Practice, 14, 1, 65-74.

Colasanti, K., Hamm, M. and Litjens, C. (2012) The city as an "agricultural powerhouse"? Perspectives on expanding urban agriculture from Detroit, Michigan". Urban Geography, 33, 3, 348-369. 
p. 250. The underutilized role of community gardens in improving cities' adaptation to climate change: A review

Cretney, R. (2014) Resilience for Whom? Emerging critical geographies of socioecological resilience. Geography Compass, 8, 9, 627-640.

Dennis, M., Armitage, R. and James, P. (2016) Social-ecological innovation: Adaptive responses to urban environmental conditions. Urban Ecosystems, 19, 3, 10631082.

Demuzere, M., Orru, K., Heidrich, O., Olazabal, E., Geneletti, D. and Orru, H. (2014) Mitigating and adapting to climate change: Multi-functional and multi-scale assessment of green urban infrastructure. Journal of Environmental Management, 146, 107-115.

Dubbeling, M. (2015) Integrating urban agriculture and forestry into climate change action plans: Lessons from Western Province, Sri Lanka and Rosario, Argentina. RUAF Foundation. RUAF Foundation. Available at: http://www.ruaf.org/publications/integrating-urban-agriculture-and-forestryclimate-change-action-plans

Ghose, R. and Pettygrove, M. (2014) Urban Community Gardens as Spaces of Citizenship. Antipode, 46, 4, 1092-1112.

Gill, S.E., Handley, J.F., Ennos, A.R. and Pauleit, S. (2007) Adapting cities for climate change: The role of the green infrastructure. Built. Environ., 30, 97-115.

Lawson, L. J. (2005) City bountiful: A century of community gardening in America. Berkeley and Los Angeles, CA: University of California Press.

Leichenko, R. (2011) Climate change and urban resilience. Current Opinion in Environmental Sustainability, 3, 3, 164-168.

Mason, E. and Montalto, F. A. (2015) The overlooked role of New York City urban yards in mitigating and adapting to climate change. Local Environment, 20, 12, 1412 1427.

McPhearson, T., Hamstead, Z., and Kremer, A. (2014) Urban Ecosystem Services for Resilience Planning and Management in New York City. Ambio, 43, 4, 502-515.

Mehmood, A. (2016) Of resilient places: planning for urban resilience. European Planning Studies, 24, 2, 407-419.

Miller, C. (2003) In the sweat of our brow: Citizenship in American domestic practice during WWII-Victory Gardens. Journal of American Culture, 26, 3, 395-409.

Okvat, H. and Zauta, A. (2011) Community gardening: A parsimonious path to individual, community, and environmental resilience. American Journal of Community Psychology, 47, 3-4, 374-387.

Passidomo, C. (2016) Community gardening and governance over urban nature in New Orleans Lower Ninth Ward. Urban Forestry \& Urban Greening, 19, 271-277.

Purcell, M. and Tyman, S. K. (2015) Cultivating food as a right to the city. Local Environment, 20, 10, 1132-1147.

Shaw, K. (2012) "Reframing" Resilience: Challenges for Planning Theory and Practice. Planning Theory and Practice, 13, 308-312.

Shaw, K. and Maythorne, L. (2012) Managing for local resilience: Towards a strategic approach Public Policy and Administration, 28, 1, 43-65.

Tanner, T., Mitchell, T., Polack, E. and Guenther, B. (2009) Urban Governance for Adaptation: Assessing Climate Change Resilience in Ten Asian Cities. IDS Working Papers, 315, 1-47.

Staeheli, L. A., Mitchell, D. and Gibson, K. (2002) Conflicting rights to the city in New York's community gardens. GeoJournal, 58, 2, 197-205.

Staeheli, L. A. (2008) Citizenship and the problem of community. Political geography, $27,1,5-21$.

Tidball, K.G. and Krasny, M.E. (2007) From risk to resilience: What role for community greening and civic ecology in cities? In: Wals, A.E.J. (ed.) Social learning towards a more sustainable world. Wagengingen: Wagengingen Academic Press: pp. 14964. 
p. 251. The underutilized role of community gardens in improving cities' adaptation to climate change: A review

Vale, L. J. (2014) The politics of resilient cities: whose resilience and whose city? Building Research and Information, 42, 2, 191-201.

von Hassell, M. (2005) Community gardens in New York City: Place, community, and individuality. In: Barlett, P.F. (Ed.) Urban place: Reconnecting with the natural world. Cambridge, MA: MIT Press: pp. 91-116.

von Hassell, M. (2002) The struggle for Eden: Community gardens in New York City. Westport, Conn. Bergin and Garvey.

Walker, S. (2016) Urban agriculture and the sustainability fix in Vancouver and Detroit. Urban Geography, 37, 2, 163-182.

Wamsler, C., Brink, E. and Rivera, C. (2013) Planning for climate change in urban areas: From theory to practice. Journal of Cleaner Production, 50: 68-81.

Wilkinson, C. (2012) Urban resilience: What does it mean in planning practice? Planning Theory and Practice, 13, 2, 319-324. 